\title{
Health of tomorrow's doctors: obstacles to appropriate help-seeking
}

\author{
Robert M. Wrate \& Pamela J. Baldwin
}

During the research interviews for Isobel Allen's prospective studies of medical careers (Allen, 1994), many young doctors voiced concerns about their working conditions. Although a relationship between doctors' health impairment and their arduous working conditions has only recently been empirically established (Baldwin et al, 1997a), concern about sick doctors, at all stages of their careers, has been growing for many years. There are very few empirical data on sick doctors' helpseeking, but the enlightened self-interest of trusts and health boards may become an important new driving force, because of the more clearly defined responsibilities of National Health Service (NHS) senior staff for the well-being of their colleagues and possible liability for colleagues' impaired clinical practice (General Medical Council, 1995; British Medical Journal, 1997). The anticipated UK shortage of doctors may also act as a stimulus for measures designed to encourage the retention of a healthy medical workforce.

Doctors are at greater risk of mental health impairment than comparable professional groups (Harrington, 1990; Hale, 1992; Silvester et al, 1994). However, other occupational groups in the NHS may be similarly stressed or their health even more impaired. Using the GHQ-12 as a measure of minor psychiatric disorder, Borrill et al (1996) demonstrated that NHS managers had the highest prevalence of mental health problems $(33.4 \%$ compared with $28.5 \%$ for nurses and $27.8 \%$ for doctors). None the less, within the medical profession at least, doctors' particular occupational circumstances are considered to require special health care provision. In addition to the National Counselling Scheme for Sick Doctors, there are several other peer support schemes in Britain (e.g. within anaesthetics), and for doctors with addiction problems. Medical associations in some other countries have developed more comprehensive treatment schemes for sick colleagues (e.g. in North America and in Australia). At a more local level in Britain some NHS trusts, general practitioner (GP) committees, and postgraduate boards have established schemes for the counselling or treatment of local doctors seeking help for mental health problems.

The British Medical Association (BMA) introduced its Stress Counselling Service in April 1996 to provide sick doctors throughout Britain with a measure of treatment. This consists of confidential counselling by CareAssist, an independent employee assistance programme. Since its launch, calls to the pilot scheme have reportedly averaged around 300 a month. Recently announcing a three year extension of this scheme, the BMA reported that in contrast to CareAssist's experience of other groups of clients, doctors' work rather than their personal lives was the most frequently observed source of stress, work affecting home life rather than the other way round (Armstrong, 1997). However, in most other respects the scheme is similar to other counselling contracts, posing the question of whether the health care needs of stressed doctors really are very different from those of other professional groups.

It is possible that doctors with more severe mental health problems have care needs that are more distinctive than those of other professions. Those describing the psychiatric treatment of sick colleagues certainly emphasise their special treatment needs (e.g. Myers, 1994), and in the

Robert Wrate is a consultant in adolescent psychiatry at the Royal Edinburgh Hospital, undertaking two prospective studies into mental health of the NHS workforce with Dr Baldwin. His interest in this work developed from clinical work with the medical families of adolescent patients, and the under-recognition of affective disorders in particular. Pamela Baldwin is a clinical psychologist and senior researcher at the Well at Work Research Unit at the Astley Ainslie Hospital, 133 Grange Loan, Edinburgh EH9 2HL. She has had a long-standing interest in medical undergraduate education and in stress within the workplace, and is currently involved in research focusing on postgraduate medical and surgical training. 
findings of the recently published study of sick doctors it was apparent that sick doctors' perceptions of obstacles to their health care, and to their resumption of clinical duties, included many issues particular to the practice of medicine (McKevitt et al, 1996).

In this paper, we provide an account of recent empirical work on the health behaviours of doctors, and offer a view on some of the main obstacles to appropriate help-seeking. We begin with an update on current NHS Executive research initiatives, and summarise some of the early findings of a prospective study in Edinburgh of the health attitudes and well-being of young doctors (Baldwin et al, 1997b). We then summarise the main points made at a 1995 Royal College of Psychiatrists workshop on sick doctors, initiated by Fiona Caldicott during her last year in office as President of the College, which we present with the following caveats. These points, which do not formally represent a College view, were largely based upon personal observations, generally unsupported by empirical data, and were not necessarily shared by the majority of those present at the meeting. None the less, we feel they are of considerable interest. Holland's findings on doctors' health behaviour are reviewed, and the findings and implications considered in the light of recommendations made in the recent report of a working party on sick doctors and their health care needs, convened under Sir Maurice Shock's chairmanship at the Nuffield Provincial Hospitals Trust (Nuffield Provincial Hospitals Trust, 1996).

\section{Mental health of the NHS workforce}

Three projects were funded by the NHS Executive's research and development division four years ago, each developed from existing studies or methodologies. The first project was continued support for a follow-up of Firth-Cozens' well-known cohort of doctors (Firth-Cozens, 1987, 1990), who were first assessed as fourth-year undergraduates and are now in their mid-30s. Although the persistently higher rates of depression found for women hospital doctors may largely reflect gender differences in the general population, it may also be the consequence of women's particular disadvantage in a career widely deemed to be inflexible, with few opportunities for moving in and out of work, and for part-time work, where personal mentoring is infrequent and few women hold senior positions.
The second project was a large-scale survey covering NHS staff of all types by Wall, Shapiro and colleagues at the Institute of Work Psychology in Sheffield. This study, whose preliminary findings for doctors, nurses, and managers have already been referred to, is being carried out in 19 different trusts, incorporating qualitative and longitudinal measures and an examination of organisational factors which affect staff well-being (Borrill et al, 1996).

The third project is a follow-up of a class-cohort of trainee doctors who were first interviewed in the autumn term of their first undergraduate year, and it is the only one of the three to examine helpseeking directly. It had been set up in 1986 by Patrick Miller and his colleagues at the MRC Social Psychiatry Unit in Edinburgh, in association with a parallel study of first-year medical undergraduates at a US medical school (Miller \& Surtees, 1991). This study had two main strengths: a wide variety of standardised psychological measures (including past family relationships, recent life events, current social supports, and personality functioning); and (uniquely among such studies) a very high rate of compliance $-97 \%$ of possible subjects were responders. Over the course of their first university year, Miller and his colleagues demonstrated that in a minority of medical students the amount of social contact they had experienced appeared to have increased their problems in adaptation (Miller \& Lloyd, 1991). Contact with the yearcohort was re-established in 1993, when most were working as senior house officers in British hospitals.

As all three studies are now entering the final phase of their follow-ups, opportunities should soon emerge to compare and contrast their findings and begin the development of policy recommendations for the NHS.

\section{Follow-up of the Scottish medical students}

When the cohort was re-interviewed in 1993, similar standardised interview methods were employed to those originally used by Miller and his colleagues. In addition, measures were included to assess perceived working conditions and subjects' health attitudes and behaviours. The two annual follow-ups since have been based on self-report questionnaires. The cohort has been interviewed again over the winter of 1996-7. Most results refer to the 1993 follow-up, when 177 out of the original 181 first-year medical students 
consented to be interviewed. This included 12 who did not complete their medical degree (i.e. a total of 165 graduates in medicine). Most of these ( $n=142$ ) were working in 1993 as senior house officers, principally in mainland British hospitals. They were mainly working in general medicine, obstetrics/gynaecology, paediatrics or in accident and emergency. The main measure of mental health was the GHQ-28 (Goldberg \& Hillier, 1979).

\section{Hours worked and health impairment}

In 1993, long working hours were commonplace, with a third of respondents exceeding Government guidelines; the findings for 1994 were no different. Long hours of work were not associated with GHQ-28 subscales of anxiety or depression, but hours were significantly associated with impairment measured by the somatic and the social dysfunction subscales $(r=0.25, P=0.002$ and $r=0.18$, $P=0.02$, respectively). These subscales include such items as concentration problems and difficulties making decisions.

\section{Mental health status}

One-fifth reported at least one episode of persistent anxiety over the previous year, and 35\% reported episodes of unexplained lethargy. The level of psychiatric caseness, as measured by the GHQ-28 with $4 / 5$ threshold, was similar to that found in the subjects' third term in their first undergraduate year $(37 \%)$. However, nearly half of those reaching caseness in 1993 had not previously been cases. Current mental health status was correlated with previous GHQ status as first-year medical students ( $r=0.34, P=0.0001)$. Student self-esteem, as measured by the Rosenberg scale (Rosenberg, 1965), was likewise a significant if modest predictor of subsequent GHQ status. No direct association was found between anxiety and depression subscales and working conditions, but more detailed analyses demonstrated a significant relationship between these measures of mental health, subjects' attitudes to work, and their working conditions (Baldwin et al, 1997a).

\section{General health, health attitudes and sickness absence}

Minor illness episodes were quite frequent, but most $(52 \%)$ had taken no time off during the previous year, and only $15 \%$ had done so more than once. Minor illness episodes provided one means of exploring respondents' health attitudes. 'Presenteeism' was common: most $(81 \%)$ reported having worked through illness where they would have advised a friend or colleague to take time off; this happened significantly more often in women (average of 4.6 days in the last year $v .3 .1$ days for men). Self-prescription was commonplace: $34 \%$ had not been registered with a general practitioner (GP), and most professional consultations had been informal, from a friend or colleague.

Illness behaviour was also assessed by their responses to a number of hypothetical illness episodes. These revealed attitudes characterised by stoicism and denial (Baldwin et al, 1997b). For example, $61 \%$ assumed they would still go to work having been awake all night vomiting, preferring to wait to see what happens rather than take time off or consult anyone; $83 \%$ believed that they would behave likewise after 12 hours of persistent haematuria. Less than a third felt that they would seek a formal consultation after noticing a growing dependence on alcohol.

\section{Attitudes to occupational health}

Many had had no contact with their hospital's occupation health department (i.e. no screening on appointment), often having little or no idea where it was located. Most considered a consultation would be confidential, but fewer than half considered such a consultation would be useful for mental health problems. For example, for assessing fitness for return to work, only $37 \%$ thought the department would have any role for a doctor who had been off work with alcohol dependency, and only $24 \%$ where a doctor had been off ill with depression.

\section{Why doctors are a special case: the 1995 College meeting}

Doctors' central role in the care of patients within the National Health Service (NHS) is widely recognised (Donaldson, 1994), but high rates of mental health problems have been demonstrated in other professional groups (e.g. Caplan, 1994; Silvester et al, 1994), favouring an argument against researching or treating doctors as a special occupational group. For instance, it has been argued that the same stressful environment is experienced by other health professionals on a 
daily basis (e.g. by nurses), that law or accountancy constitute equally competitive professional environments, and that the stress associated with doctors' out-of-hours duties may differ little from that of veterinarians on-call at night and weekends.

The majority of those present at the College meeting seemed to find such arguments unconvincing. None of these occupational groups suffers the medical profession's twin afflictions of a comparatively high suicide rate and alcoholism with a remarkably low sickness absence rate; less than a sixth of the sickness absence rate of nurses, less than a third that of NHS managers (Institute for Employment Studies, 1994, p. 12). Furthermore, if they were to become ill, no member of any of these other professional groups would be treated by their colleagues. Boxes 1 and 2 list the problems described by many at the College meeting as arguments in favour of doctors as a distinctive group in occupational health terms.

\section{Recently sick doctors}

McKevitt et al's (1996) interview-based study recorded the experience of 64 recently sick doctors. It is therefore of considerable interest, although the methodology limits generalisation of findings. It was a volunteer study. Half of the subjects were interviewed by telephone rather than face-to-face, less than half had been suffering from a psychiatric disorder, and the experience of doctors with recurring conditions was not obtained. A summary of main findings and conclusions is provided below.
Self-diagnosis and referral were often problematic; insider status and knowledge seemed to confer advantages and disadvantages. There was a commonly reported pattern of a conflict of interest in the doctor colleague consulted, between their concern about maintaining the clinical service they were responsible for and their duty of care for their patient colleague. A pressure to avoid sickleave was very widely shared. Colleagues' attitudes and the level of support they provided seemed quite often coloured by pre-existing relationships, but good emotional support did not necessarily guarantee effective practical advice. Obtaining guidance on the career implications of illness appeared fortuitous, with many unmet needs apparent. Although most doctors' experience of the treatment they finally received was very positive, problems within the dynamics of the treating doctor/sick doctor relationship seemed quite common, for example the treating doctor appearing embarrassed, anxious about their perceived competence, reluctant to take charge of the consultations, or assuming knowledge on the patient's part that they did not have.

\section{Comment}

The new follow-ups of the Scottish cohort suggest that working conditions directly affect the physical health, and ultimately the mental health, of junior doctors, and confirms the impression of doctors as an occupational group that looks after its own health in undesirable ways. These habits may extend to treating members of their own family

Box 1. Why doctors are vulnerable

Doctors' excessive workloads, with out-of-hours on-call duties extending throughout their careers and, in the case of many junior doctors and GPs, working at night and weekends in states of comparative professional isolation at reduced rates of pay.

The relative inflexibility of medical career pathways in the UK, discouraging a career change to more compatible, less onerous, or to part-time posts.

Doctors' primary clinical duties and traditional distant role from administration or management have left them poorly prepared or supported to deal with the amount of administrative paperwork that has followed NHS reforms.

Doctors' professional obligation to continuous duty of care and, although perhaps no different from nursing, prolonged exposure to patients' pain and distress and relatives' needs.

Medical practice has no well-established pattern of locum cover available to cover sick-leave, which was felt inevitably to promote doctors' increasing or entrenched stoicism, and their denial of stress or episodes of impaired well-being, even when clinical practice has become affected. 
Box 2. Why it is hard for doctors to get help

Doctors avoid formal consultations where ill-health is suspected, fearing loss of confidentiality.

When they are ill, doctors can and do behave differently from most other professional groups because of the opportunity to self-prescribe.

Ethos of stoicism, coupled with poor provision for sick-leave cover within the NHS.

Once established illness is present, doctors generally wish to be treated as patients, but despite considering themselves knowledgeable, may hold inaccurate views about treatment methods and their colleagues' practice.

Fear of stigmatisation, especially possible effects on career advancement and working relationships, which may be greater in medicine than in other professions.

Inflexible medical career pathways discourage appropriate career changes.

(La Puma et al, 1991). In addition, long working hours may be affecting their clinical performance as doctors, adding to their stressful working lives if not directly affecting their patients' treatment. Informal systems of professional support for health problems appear to represent the mainstay for most junior doctors, rather than formal consultation - an unfavourable climate for the prompt and effective treatment of mental health problems when these do present.

Fears of stigmatisation, lack of knowledge and familiarity with the occupational health department's responsibilities, and little inclination toward independent health consultations all seem important obstacles to appropriate mental health care. Some of this could be easily dealt with (e.g. by trusts ensuring all newly appointed doctors register with a local GP). Opening a wider channel of communication between mental and occupational health professions, perhaps with joint training events, should facilitate a greater understanding of the contribution of each and perhaps pave the way for more specialised training. On the other hand, however the problems of stigma and stoicism are addressed, manpower shortages and budgetary constraints now severely limit the opportunity for locum cover and do little to discourage 'presenteeism'.

Employer complacency can no longer be afforded. For example, their responsibilities under health and safety legislation for the well-being of their employees have been tested in the courts on two notable occasions. Policemen traumatised while carrying out their duties during the Hillsborough stadium tragedy recently brought a successful action against their employers, and in an earlier landmark judgement the Courts found against a council social work department after one of their managers suffered a recurrence of mental illness after returning to work from sick-leave.
Following that case, employer's duties were summarised thus:

Where it is reasonably foreseeable to an employer that an employee might suffer a nervous breakdown because of the stress and pressures of his workload the employer is under a duty of care, as part of the duty to provide a safe system of work, not to cause the employee psychiatric damage by the volume or character of the work which the employee is required to perform (New Law Journal, 2 December 1994, Walker $v$. Northumberland County Council).

Responsibility for sick doctors should not rest solely with those in management positions. The unresponsive attitudes of colleagues to the alcohol problems of a surgeon were recently criticised in court, where the British Medical Journal reported some of the judicial findings:

there appears to be a culture among members of the medical profession where it is regarded as inappropriate, or in some instances potentially injurious to future career prospects, to report on certain matters, including a colleague's apparent excessive drinking (British Medical Journal, 1997).

As a psychiatrist, Kay Jamison has spoken of her own colleagues' failure to address her increasingly manifest bipolar symptoms (Jamison, 1996), and qualitative research data emphasise the importance of colleagues' attitudes (McKevitt et al, 1996). Allen's work suggests that for trainees the influence of senior staff is sometimes decisive (Allen, 1994), but NHS reforms have placed senior staff under additional burdens that may directly compete with their obligations to trainees, whose contracts are generally insufficiently detailed to ensure provision of support and supervision. The introduction of educational contracts might improve appropriate problem-solving within the trainee's placement, and would also encourage recognition of the appropriate first steps that 
should be undertaken when a trainee appears to become unwell.

Many different authorities or groups currently have some responsibility for the work or functioning of doctors (Donaldson, 1994), but it is presently unclear which role each should assume when a doctor becomes ill, how communication should occur, and how decisions should be made. Fragmentation of responsibility may act as a further barrier to the effective care of doctors who become sick (McDonald \& McCoy, 1994). Improved coordination of services has been recommended, and the Nuffield working party on sick doctors proposed that postgraduate deans should assume a central role (Nuffield Provincial Hospitals Trust, 1996). We do not know how widely this has been accepted.

Although we know far more now about doctors' health and health behaviours than we did 10 years ago, and detailed individual accounts of their clinical treatments have been published (e.g. Chick, 1992; Myers, 1994), very little is known about how treatment is generally provided, its sometimes complex relationship to the profession's regulatory or disciplinary procedures, and next to nothing about the outcome of treatment, for instance the success of the various new local or national schemes for sick doctors in the UK. Concern to preserve confidentiality has probably prevented an adequate evaluation of the provision of such treatment, but as mental health problems tend to re-occur, a robust knowledge of effective procedures that could be widely replicated is vital.

However effectively such issues are addressed, until the stigma of mental ill health is successfully challenged it is likely to continue to be an important deterrent to appropriate help-seeking. Such stigma, which probably also applies to mental health services, may be little different within the medical profession from that of the wider public. Destigmatisation within the profession would make an important contribution to the welfare and prompt treatment of sick doctors. Recom mendations to promote appropriate help-seeking are summarised in Box 3.

Box 3. Some recommendations to promote appropriate help-seeking

Identify means of reducing the social and professional isolation of junior doctors working outof-hours.

Improve junior doctors' training culture by the introduction of well-defined educational contracts for postgraduate training posts, facilitating the provision of appropriate levels of support and the prompt recognition of any aspect of this which becomes seriously inadequate.

Support consultant trainers' supervisory role by increasing administrative support for their other non-clinical duties.

Encourage more open acknowledgement of the impact of prolonged exposure to patients' pain, relatives' distress, and treatment failure; improving junior doctors' discrimination between appropriate and inappropriate self-criticism.

Identify various means to reducing doctors' inappropriate stoicism when ill, by improving access to primary care for those developing illnesses, actively discouraging self- or colleagueprescription from hospital pharmacies, and by improving arrangements for sickness cover.

These procedures should be specifically included in job contracts, e.g. trusts' initial occupational health procedures should include facilitating the registration of incoming staff at local GP practices.

Further qualitative research on sick doctors is required, on the impact of illness on their work, and on experience of their treatment, which would assist the development of models of good practice.

Improve junior doctors' knowledge of the impact of significant illness episodes upon doctors' work, and of models of good practice for their successful management.

Establish better defined and more coherent lines of accountability and responsibility for the health and well-being of doctors in general practice and in permanent hospital posts.

Develop a clearer definition of the roles and responsibilities of the various innovations for sick doctors that have evolved over the past 20 years, in particular identifying complementary and overlapping functions in areas served by several schemes and evaluating their outcomes.

Reduce stigmatisation within the medical profession, perhaps by greater joint working.

Improve the flexibility of medical career pathways in the UK, to increase the scope for changes in career direction following ill-advised early choices or because of illness. 


\section{Acknowledgements}

For the Edinburgh research project we are indebted to the previous work of Patrick Miller, and to our group of advisers, including S. Platt, M. Porter, A. Cremona and R. Agius, and to Marjorie Dodd, without whom the operational burden of the research would be overwhelming. The research is funded by the NHS Management Executive R \& D Division.

\section{References}

Allen, I. (1994) Doctors and their Careers: A New Generation. London: Policy Studies Institute.

Armstrong, E. M. (1997) Vital stressline is set to continue. BMA News Review, 23, 4.

Baldwin, P. J., Dodd, M. \& Wrate, R. M. (1997a) Young doctors' health: how do working conditions affect attitudes, health and performance. Social Science and Medicine, 45, 34-40.

,$--\&-(1997 b)$ Young doctors' health: health and health behaviour. Social Science and Medicine, 45, 41-44.

British Medical Journal (1997) Inquiry calls for doctors to be tested regularly for alcohol. British Medical Journal, 314, 769.

Borrill, C. S., Wall, T. D., West, M.A., et al (1996) Mental Health of the Workforce in NHS Trusts: Phase 1 Final Report. Sheffield: Institute of Work Psychology, University of Sheffield.

Caplan, R. (1994) Stress, anxiety and depression in hospital consultants, general practitioners and senior health service managers. British Medical Journal, 309, 1261-1263.

Chick, J. (1992) Doctors with emotional problems: how can they be helped? In Practical Problems in Psychiatry: Some Clinical Guidelines (eds K. Hawton \& P. Cowen). Oxford: Oxford University Press.

Donaldson, L. (1994) Sick doctors: a responsibility to act. British Medical Journal, 309, 557-558.

Firth-Cozens, J. (1987) Emotional distress in junior house officers. British Medical Journal, 295, 533-536.
- (1990) Sources of stress in women junior doctors. British Medical Journal, 301, 89-91.

General Medical Council (1995) Good Medical Practice. London: GMC.

Goldberg, D. P. \& Hillier, V. F. (1979) A scaled version of the General Health Questionnaire. Psychological Medicine, 9, 139145.

Hale, R. (1992) The cobbler's children: how the medical profession looks after its own. British Journal of Hospital Medicine, 47, 405-407.

Harrington, J. M. (1990) The health of health care workers. Journal of the Royal College of Physicians, 24, 189-195.

Institute for Employment Studies (1994) Health at Work in the NHS: Key Indicators. Document CN1764. Brighton: University of Sussex.

Jamison, K. R. (1996) An Unquiet Mind: A Memoir of Moods and Madness. London: Picador.

La Puma, J., Stocking, C. B., La Voie, D., et al (1991) When physicians treat members of their own families. New England Journal of Medicine, 325, 1290-1294.

Miller P. McC. (1995) The importance of context in who needs and who does not need social support among college students. In Social Support and Psychiatric Disorder: Research Findings and Guidelines for Clinical Practice (ed. T. S. Brugha), pp. 163-173. Cambridge: Cambridge University Press.

- \& Lloyd, C. (1991) Social support and its interactions with personality and childhood background as predictors of psychiatric symptoms in Scottish and American medical students. Social Psychiatry and Psychiatric Epidemiology, 26, 171-177.

— \& Surtees, P. G. (1991) Psychological symptoms and their course in first-year medical students as assessed by the Interval General Health Questionnaire (I-GHQ). British Journal of Psychiatry, 159, 199-207.

MacDonald, E. B. \& McCloy, E. C. (1994) Existing services need to be coordinated (letter). British Medical Journal, 309, 1235.

McKevitt, C., Morgan, M., Simpson, J., et al (1996) Doctors' Health and Needs for Services. London: Nuffield Provincial Hospitals Trust.

Myers, M. F. (1994) Doctors' Marriages: A Look at the Problems and Their Solutions (2nd edn). New York: Plenum.

Nuffield Provincial Hospitals Trust (1996) Taking Care of Doctors' Health. London: NPHT.

Rosenberg, M. (1965) Society and the Adolescent Self Image. Princeton, NJ: Princeton University Press.

Silvester, S., Allen, H., Withey, C., et al (1994) The Provision of Medical Services to Sick Doctors: A Conspiracy of Friendliness? London: Nuffield Provincial Hospitals Trust. 